\title{
Rehabilitation of the Nine-banded Armadillo (Dasypus novemcinctus)
}

\author{
SuZANne McPheE AND Nancy Leary \\ Northridge, CALIFornia
}

\section{INTRODUCTION}

The following is a sampling of substitute formulas, diets, caging facilities, specialized care, and release criteria for the nine-banded armadillo (Dasypus novemcinctus). The information presented should be used as a guideline, not an absolute.

\section{HISTORY}

Armadillos are prehistoric animals related to anteaters (Cyclops, Myrmecophaga, Tamandua spp.) and sloths (Bradypus, Choloepus spp.). They originate in South and Central America where there are 20 different species. Specie sizes range from the size of a guinea pig up to that of a St. Bernard (Ramsey 1978). Only the threebanded armadillo (Tolypeutes matacus) is able to roll into a ball. Armadillo is a Spanish word meaning small animal in armor.

\section{RANGE}

The nine-banded armadillo's range occupies Texas, Alabama, Arkansas, Georgia, Florida, Louisiana, Mississippi, southern Kansas, and Oklahoma. The nine-banded armadillo is believed to have expanded its range from Mexico into the US as settlement in Texas and surrounding states removed natural barriers that prevented range expansion. The armadillo population in Florida and bordering states is most likely from an intentional introduction. Their range is restricted by temperature and aridity because they do not hibernate or store fat. Also, armadillos do not have fur to protect them from extreme high or low temperatures, which further limits their range. Armadillos prefer habitats with heavy brush or woodlands where the soil is easy to dig and there is plenty of available water.

Suzanne McPhee is a wildlife educator and wildlife rehabilitator specializing in the nine-banded armadillo and has successfully bred this species in captivity. She is currently researching behavior and conducting studies on monozygotic quadruplets and metabolic bone disease in the nine-banded armadillo.

\section{BENEFIT TO ENVIRONMENT}

Armadillos are omnivorous, but 90 percent of the diet is insect pests/larvae, including ants, grubs, fire ants, and earthworms. While digging for insects, they aerate the soil that is beneficial for plant seeding. Armadillos also provide habitat with their burrows, as many other species will use them for shelter.

\section{DESCRIPTION, CHARACTERISTICS, AND BEHAVIOR}

Adult Description. The head and body of the adult is 35 to $44 \mathrm{~cm}$ (14 to 17 in); tail 35 to $40 \mathrm{~cm}$ (14 to $16 \mathrm{in}$ ); weight 3.6 to $7.7 \mathrm{~kg}$ (8 to $15 \mathrm{lbs}$ ); and the body is a brownish-gray color. The head, body, and tail are covered with a leathery material that protects the animal. The underside is very soft, wrinkled, and covered with fine hair; the tail is long and tapered. The nine-banded armadillo has 7 to 11 movable bands near the center of the body. The body shell, called the carapace, is a modified keratinous (fingernail-like material) skin structure. The front of the carapace is the scapular shield, with bands in the middle, and the pelvic shield is the rear portion of the carapace. They have short, fine hair that is very sensitive all over the body. When these hairs are stimulated, such as when a car passes over, the animals tend to jump straight up. Physiologically armadillos are equipped for burrowing and rooting, and are active diggers. The front feet have four toes and large claws, and the back feet have five toes and large claws (Figure 1). No incisors or canine teeth are present; although they do have 32 peg-like, non-enameled molars. Armadillos have long protrusive tongues with sticky saliva, a pig-like nose, and large ears that can rotate independently to locate a noise. The animals also have two retractable anal scent glands under their tail which evert during stress. Armadillos are fullgrown and sexually mature at one and a half years of age. Armadillos have a urogenital sinus. The female looks much like the male with an external sheath, but has a cleft that leads to the urogenital sinus. Nursing 


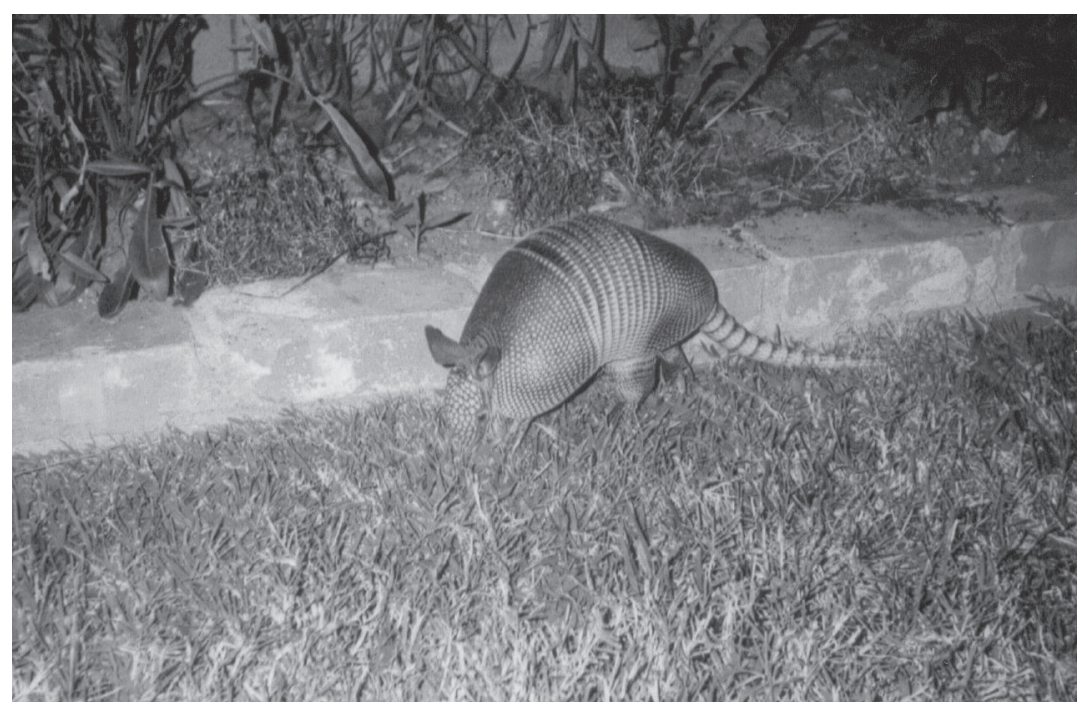

Figure 1. Armadillo at six months of age.

female armadillos are not obvious to detect, as they do not bag up like other mammals. The milk is interspersed between layers of skin. Males do not have an external scrotum.

Body Temperature-The normal body temperature of an armadillo is 87 to $95^{\circ} \mathrm{F}\left(30\right.$ to $\left.35^{\circ} \mathrm{C}\right)$; they are unable to perspire, making heat stress more serious than cold stress, but both temperature extremes should be avoided. This inability to maintain a constant body temperature causes extremes or rapid changes in temperature to be deadly for armadillos.

Senses-The sense of smell is the most developed sense, while hearing is average, and eyesight is poor. Armadillos are able to locate insects 12 to $15 \mathrm{~cm}$ (5 to 6 in) underground by smell.

Temperament-Their normal behavior is stable (non-aggressive or non-territorial), but the long claws can scratch when trying to escape. Known predators and species of conflict tend to be the same as those that prey on rabbits, but commonly include: dogs, coyotes, bobcats, man, and cars.

Lifespan-Armadillos live 20 to 30 years in captivity given proper care and environment, and a maximum of 15 years in the wild. Normal life span in the wild is 7 to 10 years.

Activity. Armadillos are solitary in the wild, except when babies and during mating. Nocturnal in summer, they are active during night and early morning hours, although they may sometimes be seen during the day after a heavy rain. Though diurnal in the winter, particularly in the colder locales, they are active during the warmest part of the day in midafternoon. The armadillo will sleep up to 19 hours per day. Armadillos are adapted to water and will walk across the bottom of a shallow river or stream to the other side. They also can fill their intestine with air for buoyancy to swim across water. The adults can hold their breath for up to 10 minutes underwater and during digging. They dig like a jackhammer, very fast and strong, and can excavate a hole in less than one minute. Armadillos can run fast when escaping a predator; if it cannot escape by running, it will quickly dig a hole and wedge itself in with its claws. Armadillos are also capable of jumping straight upward up to three feet, and will do so when startled or frightened.

Reproduction. The female armadillo ovulates only one egg each year and is the only animal that does natural cloning. The female's single fertilized egg divides twice creating four identical quadruplets that develop with one placenta, but each embryo has its own amniotic shield. Armadillos normally have one litter a year born from February to May. The female can delay implantation of an egg in the uterus for up to three years if stressed due to environmental or physiological conditions. Typically there is a three-month delay, then a four-month development before delivery, equaling a normal gestation period of seven months. Young are born in a nest inside the burrow and are precocial, fully developed miniatures of the adult with eyes open and walking after birth. The infant's carapace is soft and pink at birth, then hardens and darkens within a few days. By two weeks of age, the top of the carapace shield has darkened considerably. Young nurse from the female until weaned, sometimes up to four months.

Parasites and Diseases. Due to the low body temperature, armadillos have few parasites that affect them; they will occasionally have strongyles. Because of the small gene pool (inbreeding) in the US, bone decalcification and degenerative bone disease have been found to be hereditary in armadillos. Nine-banded armadillos appear to have very inbred populations since not many have migrated far since 1850 when first introduced into the US. They are less apt than other mammals to have rabies due to the low body temperature. Other than man, armadillos are the only mammal known to harbor the leprosy bacilli, again due to low body temperature. This unusual trait prompted studies by Dr. Eleanor E. Storrs using armadillos and development of leprosy vaccines and other treatment methods in humans (Dr. Eleanor E. Storrs, 
Gulf South Research Institute, New Iberia, Louisiana, personal communication). According to the US public health service, there is no hard evidence that the armadillo can transmit leprosy to humans; only the reverse occurs (CDC 1993).

[Editor's Note: Controversy and questions of efficacy have surrounded the leprosy vaccine and its development. Scientific research and prior vaccination programs using the vaccine note a lack of efficacy. More information on the vaccine may be found at <http:// www.uow.edu.au/arts/sts/bmartin/dissent/documents/Burchfield/alc03.html>.]

\section{INFANT CARE AND WEANING}

Infant armadillos go through three developmental stages: infant (pup), juvenile, and adult. Infant armadillos weight 3 to $4 \mathrm{oz}$ ( 85 to $115 \mathrm{~g}$ ) and are 75 to 90 $\mathrm{mm}$ ( 3 to $3.5 \mathrm{in}$ ) in length from the crown (top of head to rump). They purr like kittens when nursing from the female and also make squeak, grunt, and woof noises. Infants defecate and urinate without assistance and do not need to be stimulated if being hand-raised. Infants generally look thin with prominent hips, and appear to be covered with pliable and wrinkled soft leather.

In the wild, infant armadillos will leave the burrow without the female and forage on their own early in the day. Making sure an infant armadillo that has been acquired is a true orphan and not one kidnapped during exploration, is imperative. Unless, the area has been excavated, a baby will not be seen before about one month of age. If there is uncertainty, return the young animal to the area where it was found or have people watch for several hours to make sure the female is not around.

Feeding. Infant armadillos normally gain about 0.25 $\mathrm{Oz}(7 \mathrm{~g})$ a day. Feeding is challenging, at best, due to the shape of the mouth. Tube feed only as a last resort. If tube feeding is necessary, it should be done with a red rubber urethral catheter, 8 or 10 French, or with a curved syringe with the tip cut off and filed smooth. If the infant will lap formula, provide it in a low shallow dish.

The natural diet of the armadillo is insects, indicating the female's milk is high in protein (Moore and Joosten 2002). Since no one has been able to analyze the female's milk, the closest relative for which analysis information is available is the anteater. Based on the analytical data from anteater milk, the armadillo substitute formula should be: one part re-hydrated powered Esbilac ${ }^{\circledR}$ (Peg-Ag, Inc., Hampshire, IL)
Table 1. Formula feeding amounts by weight.

\begin{tabular}{|c|c|c|}
\hline Weight (g) & $\begin{array}{c}\text { Amount (ml) 3 } \\
\text { times per day }\end{array}$ & $\begin{array}{c}\text { Amount (ml) 4 } \\
\text { times per day }\end{array}$ \\
\hline 156 & 6.8 & 5 \\
\hline 225 & 9.2 & 6.9 \\
\hline 275 & 10.75 & 8 \\
\hline 325 & 12.19 & 9.1 \\
\hline 375 & 13.57 & 10.15 \\
\hline 425 & 14.91 & 11.15 \\
\hline 475 & 16.2 & 12.12 \\
\hline
\end{tabular}

or Zoologic ${ }^{\circledR}$ (Peg-Ag, Inc., Hampshire, IL) to two parts warm water, shaken or mixed well (no clumps), and given at a temperature that is warm to the touch $\left(100^{\circ} \mathrm{F}\left[38^{\circ} \mathrm{C}\right]\right)$ but not hot. Multimilk ${ }^{\circledR}(\mathrm{Peg}-\mathrm{Ag}$, Inc., Hampshire, IL) can be added at a ratio of $1 / 4$ the amount of Esbilac ${ }^{\circledR}$. If the armadillo is having problems gaining and maintaining weight, whipping cream can be added to the formula.

The Wildlife Center in Burroughs Park, Tomball, Texas, recommends that when feeding any infant mammal, the formula be slowly introduced (John Huckabee, DVM, PAWS Wildlife Dept., Lynwood, WA, personal communication). Pedialyte ${ }^{\circledR}$ (Abbott Laboratories, Abbott Park, IL), or another electrolyte replacement fluid, should be given for the first 24 hours. Start formula introduction with one part Esbilac ${ }^{\circledR}$ to four parts water following electrolytes, then 1:3 the next feeding, and finally 1:2. It is best to work gradually into the ratio of $1: 2$, carefully observing the armadillo stool for abnormalities.

An infant has a better chance of survival if it receives the female's colostrum in the first 48 hours after birth. The female armadillo nurses the offspring frequently, but gives little milk at a one time. It is best to feed every two hours from birth to two weeks and every three hours from three weeks to weaning. Night feeding is not necessary unless the infant's condition warrants it. It is better to underfeed than overfeed. The infant stomach can hold a maximum of $50 \mathrm{ml} / \mathrm{kg}$ of body weight; over this amount and distention (bloat) problems may occur. The maximum amount to feed per day is $50 \mathrm{ml} / \mathrm{kg}$ of body weight (Table 1 ).

Weaning. In the wild, armadillos are weaned at approximately three to four months. Body length at weaning averages 15 to $17 \mathrm{~cm}$ ( 6 to 7 in) measuring from crown (top of head) to rump and the weight should be 13 to $14 \mathrm{oz}$ (370 to $400 \mathrm{~g}$ ). The coloring is still pink, but dark gray on top of body, especially behind head, and light gray on rump. 


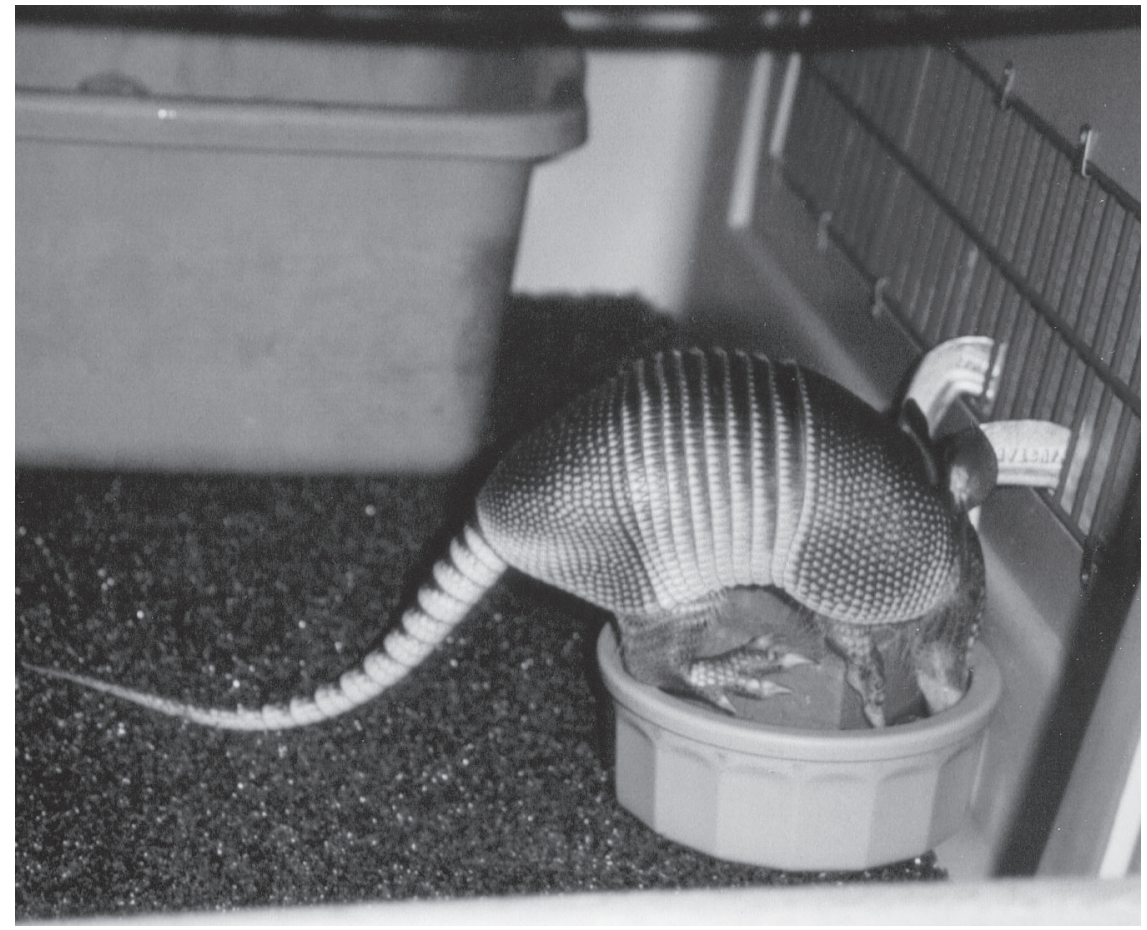

Figure 2. Bricks placed in the water bowl prevent the armadillo from getting food in its water.
Vitamins such as Blair's Super Preen ${ }^{\circledR}$ bird vitamin (Neon Pet Products, La Mirada, CA), Pet Tabs ${ }^{\circledR}$ (Pfizer Animal Health, New York, NY), or any good multivitamin supplement also may be added. In addition, sprinkle Rep-cal ${ }^{\circledR}$, a vitamin $\mathrm{D}_{3}$ and calcium supplement, (Rep-cal Research Labs, Los Gatos, CA) on top of food. Treat foods may include worms, crickets, June bugs (Cotinus nitida), grapes, bananas, pears, cooked yams, mashed fruit, and mashed hard-boiled eggs. Mistakes have been made when people try to give an armadillo an all-insect diet; in captivity they need quality cat food. Fruits and vegetables should be no more than 10 percent of the diet. Armadillos will eat solid foods at roughly three to four weeks of age and can be weaned by three months.
Begin weaning by adding moistened Dry Science Diet Feline Growth ${ }^{\circledR}$ (Hill's Pet Nutrition, Topeka, KS) in the blue bag or canned. Soak dry food in water a few hours until soft. If the infant does not eat, try mashing the moistened cat food into a soupy gruel by adding water or Esbilac ${ }^{\circledR}$ formula. Feed in a low, shallow dish. Armadillos are very messy eaters; they will walk through the food and play with it before really eating. Heavy ceramic bowls are recommended for food and water (Figure 2). Fresh water should be available at all times. A poultry waterer that has been stabilized in the cage works well for the weaning and post weaning stage.

At three months, add vitamin $K_{1}$ to the diet. Armadillos are often deficient in this nutrient. A pharmacy can mix vitamin $K_{1}$ into syrup of $5 \mathrm{mg} / \mathrm{ml}$ and supplement is administered by adding to food. Provide drops in doses of:

Juvenile-1 drop 3 times a week $(1 / 100 \mathrm{ml}$ at above noted $5 \mathrm{mg} /$ $\mathrm{ml}$ concentration).

Adult-2 drops 3 times a week.

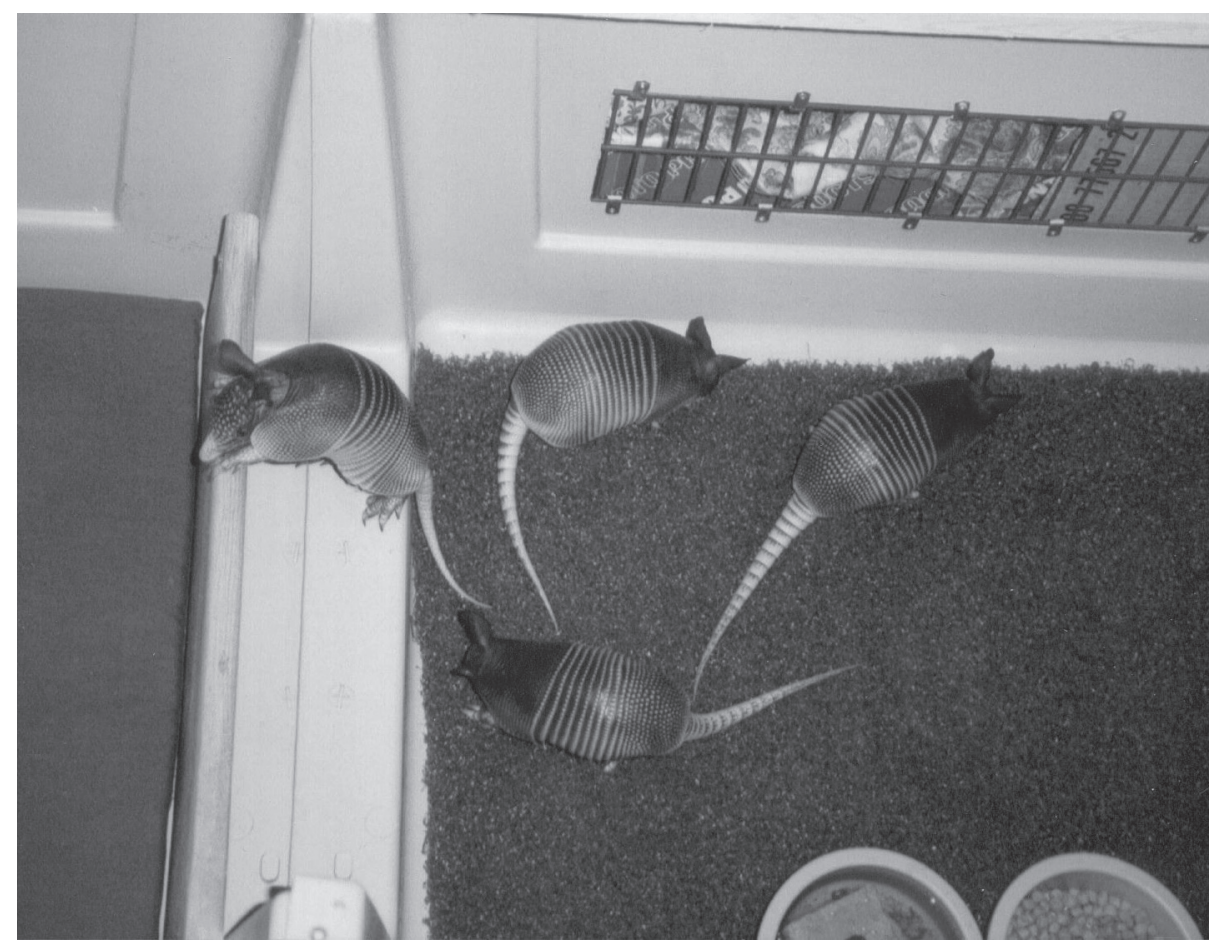

Figure 3. Male armadillos at one month of age in kennel caging.
[Author's Note: For convalescing diets, slurry can be made using Hills $A / D^{\circledR}$. This can be gently introduced with a syringe in the side of the armadillo's mouth.] 
Housing. Being a burrowing animal, the armadillo does best in housing that contains a large quantity of pesticide-free dirt to satisfy the instinct to dig. In the wild, armadillos can have as many as 15 burrows in a 10 -acre range, using some for temporary shelter from extreme heat or cold, or for escape. The burrows are usually 17 or $20 \mathrm{~cm}$ ( 7 or 8 in) in diameter and up to $4.6 \mathrm{~m}(15 \mathrm{ft})$ in length. Burrows usually are located around rock piles, trees, stumps, brush piles, etc.

Large aquariums and Varikennels ${ }^{\circledR}$ (Petmate, Arlington, TX) work well for housing pre-weaned infants. Place a heating pad on low under the container area with bedding. Avoid using bedding with strings, stuffed animals, etc. Use sweatshirt type material, cotton flannel, sports knit, or polar fleece in the cage for them to burrow under for warmth. Do not use terry cloth towels or material that will fray or has loose threads that may wrap around body parts or the tongue. Strings can act as a tourniquet causing severe problems and possibly death.

Separate the top from a Vari-kennel ${ }^{\circledR}$ and lay the two half kennel sections upright with fronts facing each other. Attach them to one another at the bottom by overlapping the crate door surround or lip on top of each other. Use rubber matting as flooring underneath the crate halves for easier cleanup (Figure 3). Secure a litter box and food at one end; place plenty of nesting material at the other end of the cage. Armadillos can break their tails by falling from heights while climbing, so low caging is safer-no higher than $2 \mathrm{ft}$ $(0.61 \mathrm{~m})$. Cover the top of the crate caging with heavy screen or at least 14 gauge wire mesh (openings should be small enough so the nose cannot fit through), overlapping the crate sides by a minimum 2 in $(5 \mathrm{~cm})$ and use hooks, clips, or weights to secure cover in place.

Offer a nest using natural bedding materi$\mathrm{al}$, such as pine needles, grass, leaves, and corn husks that can be changed daily; they prefer a clean nest. Do not use newspaper. Armadillos hold the nesting material with their front feet and hop backwards to make the nest. No sawdust, hay, or straw should be used as it can cause intestinal impaction if eaten or pneumonia if dust is inhaled. A litter box is provided by placing an 11.5 qt (10 1) Rubbermaid ${ }^{\circledR}$ (Rubbermaid, Inc., Wooster, $\mathrm{OH}$ ) dishpan container of clean dirt in the cage (Figure 4). As they grow, change to a 16 qt (15 l) dishpan as used with adults. Use fresh dirt or adobe clay if available; rabbit food pellets also may be used. Do not use cat litter! The animals play in dirt and will dig a trench with back legs for urination and defecation, which they promptly cover with their front legs after use. Beware of unknown dirt origin as pesticides may have been used. Replace dirt often, at least every other day.

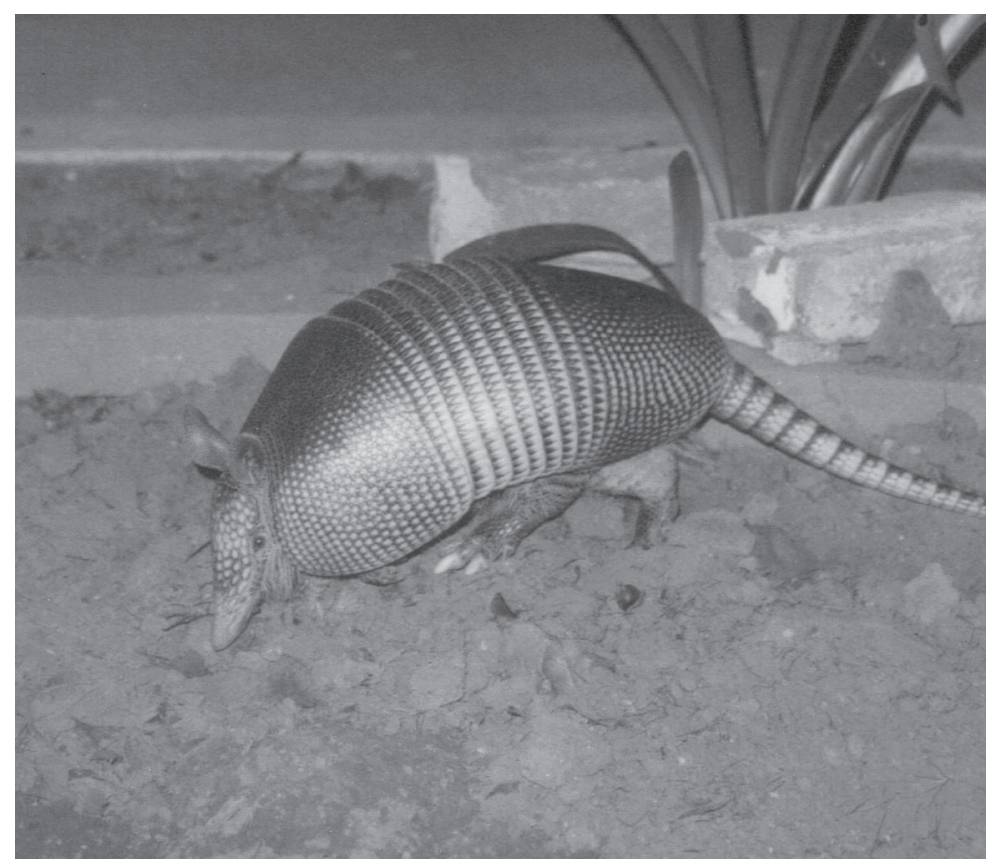

Figure 5. One-year-old armadillo outside. 


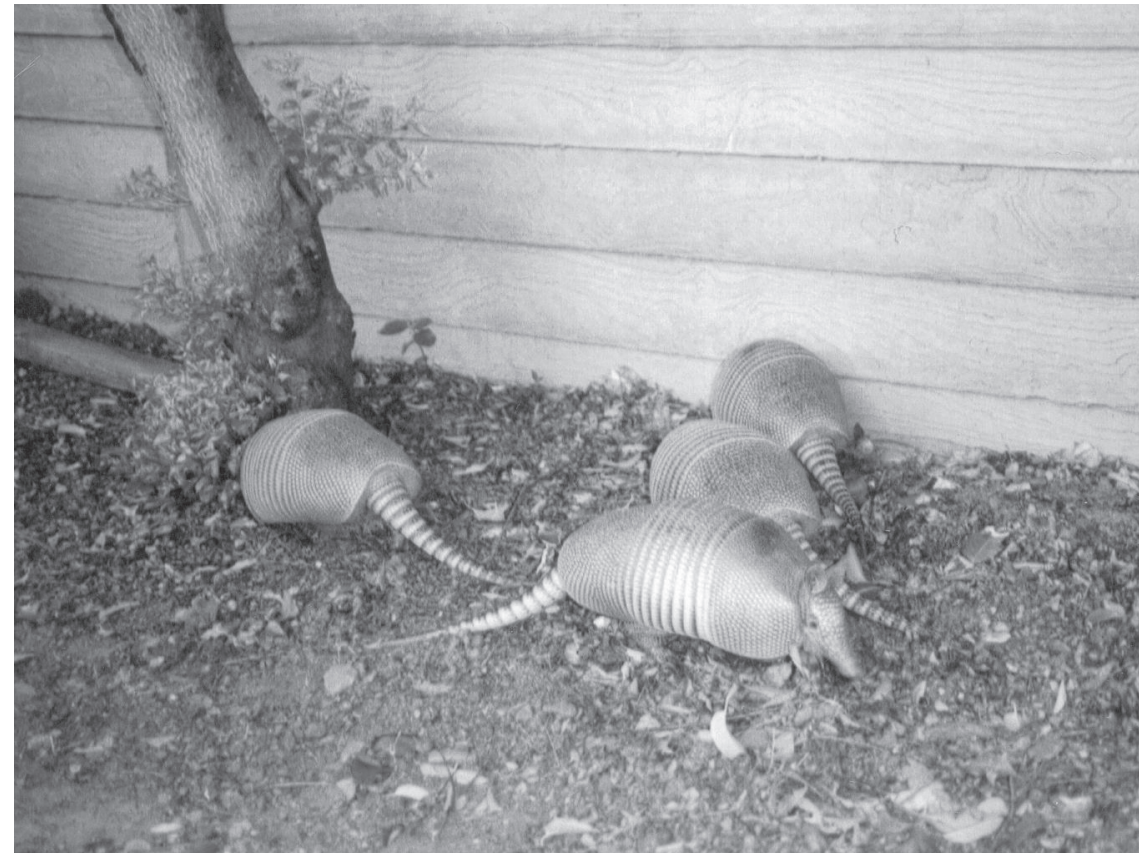

Figure 6. Armadillos nearing release are put outside daily.

Take the armadillo infant outside daily for digging activities, but keep a very close eye on it (Figure 5). Provide a pool with a couple inches of water as an additional outside activity. These activities improve chances for survival when released if skilled in rooting, digging, and being in water. If the animal cannot be taken outside, supply fresh dirt daily for rooting.

Release. The release weight of an armadillo is $1 \mathrm{~kg}(2 \mathrm{lb})$ and is based on its ability to eat on its own; each armadillo will be different according to its normal behaviors (Figure 6). If a proper environment is available to ensure natural behaviors, allowing the armadillo to grow to a larger size will make it less vulnerable to predators.

\section{MEDICAL}

Consult with a wildlife veterinarian before giving any medications. Medication dosages and types of medications are usually equivalent to those used in cats. Armadillos do not require any vaccinations. Isolate an injured or sick armadillo to ensure that others do not cause harm to it as healthy armadillos may be aggressive to those in a weakened state.

When receiving an injured armadillo, be sure to check the smallest injuries for maggots. It is not uncommon for a dehydrated animal to keep its eyes closed for several days. This can continue even after the animal has been hydrated. Also, an armadillo's nose is running constantly to keep its receptors clear for picking up the electrical impulses of insects; this natural discharge should be clear.
Injured Armadillo Care. All

incoming injured armadillos are given a dose of injectable vitamin $\mathrm{K}_{1}$ and then continued on oral $\mathrm{K}_{1}$ in their diet.

\section{Possible Conditions and Treatments.}

Abcess - When found on the carapace it should be debrided and be treated with antibiotic cream. Clavamox ${ }^{\circledR}$ (amoxicillin/clavulanic acid, Pfizer Animal Health, New York, NY) has worked well for carapace infections.

Constipation-Symptoms are often a sluggish, slow gait. Treat with mineral oil given orally; extreme caution must be used when giving mineral oil orally to avoid aspiration.

Cracked, Torn, or Damaged Shell-Severe necrotizing infection can result from traumatic injuries to the shell. Armadillos also are prone to getting abscesses in the shell that can be debrided easily. Spray the area with Naylor's Blu Kote ${ }^{\circledR}$ (H. W. Naylor Co., Inc., Morris, NY) fungicide or apply gentian violet dressing. Immediate veterinary help is generally needed. Benzathine penicillin, a long acting ( 2 to 4 weeks) penicillin drug, may be useful given intramuscularly for adult armadillos in combination with debridement of contaminated wounds. Daily application of an antibiotic ointment also works as treatment. Hydotherapy baths to flush wounds also are beneficial for healing (armadillos appear not to mind the bath).

Dehydration-Symptoms observed-a concave shell, with hips showing prominently. Treat dehydration with Pedialyte ${ }^{\circledR}$ orally for first 24 hours.

Diarrhea-Kaopectate ${ }^{\circledR}$ childrens (Pharmacia Corp., Peapack, NJ) works well. Because of allergic reactions observed in some armadillos, this author has removed Pepto Bismol ${ }^{\circledR}$ (Proctor and Gamble, Cincinnati, $\mathrm{OH}$ ) from the list of recommended medications.

In some animals diarrhea can be resolved by adding $1 / 3$ of a packet of gelatin over the food. It is normal for an armadillo's stool to vary in consistency. If other causes have been ruled out (such as coccidia) and no observation of weight loss has occurred; loose stool is normal for that particular armadillo.

Parasites-Treatment with Albon ${ }^{\circledR}$ (Pfizer, New York, NY) or Flagyl ${ }^{\circledR}$ (metronidazole, Pfizer, New York, NY) has worked well for parasites. Although this 
author has used Albon ${ }^{\circledR}$ successfully when treating coccidia, one armadillo patient had a bad reaction.

Tail injuries-Injuries to the tail should be evaluated immediately by a veterinarian. Apply antibiotic cream, wrap wound area with gauze and adhesive tape, and apply one drop of super glue at bandage edge abutting skin to help bandage stay in place until examined by a veterinarian.

Tail fractures-Fractures of the tail do not heal well due to poor circulation in the tail.

Chemical Restraint. The drugs used for chemical restraint in armadillos are: Ketaset ${ }^{\circledR}$ (ketamine hydrochloride, Wyeth, Madison, NJ), an intramuscular or intravenous immobilizing agent, and isoflurane, an inhalant (gas) general anesthetic. These drugs only should be used in consultation with a veterinarian.

[Editor's Note: In wildlife, the use of Ketamine hydrochloride alone without the addition of other drugs is not recommended (Willowbrook Wildife Center Pharmaceutical Index, 3rd edition, Pp. 15-19).]

\section{DAMAGE CONTROL IN RESIDENTIAL YARDS}

Some consider the armadillo a nuisance in their yard due to digging activities (Sramek 1987). Armadillos will frequent a well-tended garden or flowerbed, as do the insect pests they eat. Dry seasons, especially neardrought conditions, cause armadillos to search for softer soils. To deter an armadillo from digging up gardens or flowerbeds, bury chicken wire either around the fenced border of the garden, or just below the soil level in flowerbeds-slant the chicken wire outwards at about a 40-degree angle.

Removal of brush, rock piles, and tall grass sometimes will discourage armadillos from becoming established in an area. To discourage digging, the Wildlife Center in Burroughs Park recommends cayenne pepper sprinkled liberally on flowerbeds or ammonia soaked rags placed around and on the beds (John Huckabee, DVM, PAWS Wildlife Department, Lynwood, WA, personal communication).

Although not recommended, live traps are available (either by purchase or rental) for relocating an animal. When catching a wild armadillo a dip net can be used. Their tails are very sensitive and when picking up an armadillo the tail should be held at the extreme base with the body of the armadillo up against the holder's body. Check with your local animal shelter, animal control, or state parks and wildlife department about regulations and release sites before relocating armadillos.

\section{CONCLUSION}

In this author's 23 years of working with armadillos, there has been very little published material about armadillo care. The methods presented here have worked over a long period as the author has accumulated knowledge and developed good practices. A dedicated armadillo caretaker, the author is always striving to develop better methods and formulas to improve care and techniques. Sharing of information and techniques is essential to expand knowledge of these strange and wonderful animals.

\section{LITERATURE CITED}

CDC. 1993. Recommendations of the International

Task Force for Disease Eradication. Available from: <http://www.cdc.gov/mmwr/preview/ mmwrhtml/00025967.htm>.

Moore, A., and S. Joosten, eds. 2002. NWRA Principles of Wildlife Rehabilitation, 2nd edition. P. 8.23.

National Wildlife Rehabilitators Association: St. Cloud, MN.

Ramsey, C. 1978. Fact Sheet, Armadillo. Texas Agriculture Extension Service: College Station, TX.

Sramek, R. 1987. Animal Damage Control, Controlling Armadillo Damage. Texas Rodent and Predatory Animal Control. Texas A \& M University: San Antonio, TX.

[Editor's Note: For additional information from this author on armadillo care or to obtain an armadillo fact sheet, contact Suzanne McPhee at 17081 Devonshire St. Unit 6, Northridge, CA 91325. 818-368-0936.] (․ㅐㅇㅛ

\section{FROZEN: RATS, MICE \& CHICKS}

shipped anywhere in the USA www.frozenrodents.com

PERFECT PETS INC. 23180 SHERWOOD

BELLEVILLE, MI 48111

(800) 366-8794 FAX (734) 461-2858 